\title{
Formation of the list of gas industry critical objects from the standpoint of energy security of the country
}

\author{
Sergey Senderov ${ }^{1, *}$, Viktor Rabchuk ${ }^{l}$, and Sergey Vorobev ${ }^{1}$ \\ ${ }^{1}$ Energy Systems Institute SB RAS, 130 Lermontov str., Irkutsk, Russia
}

\begin{abstract}
The paper is devoted to the search for critical objects of the Russian gas industry in terms of energy security of the state and regions. The task of identifying critical objects of the gas industry is presented and an algorithm for their distribution according to the lists of federal and regional levels is shown. A list of critical facilities of the federal gas industry is presented. This list includes, along with gas transmission network objects, head compressor stations at the exits from gas fields and underground gas storages.
\end{abstract}

\section{Introduction}

When managing the development of the country's fuel and energy complex (FEC), it is necessary to take into account the requirements of energy security. In large, there are two such requirements. The first requirement is a long-term, non-deficit provision of domestic consumers with all necessary types of fuel and energy resources (FER) and fulfillment of compulsory export deliveries of Russian fuel and energy resources in the operation of the fuel and energy complex under normal conditions. The second requirement is to create conditions for ensuring domestic consumers of the country with all kinds of fuel and energy resources and export deliveries of Russian fuel and energy resources in the minimum required quantities in the event of emergency and crisis situations, without allowing significant social and economic damage from nondelivery of fuel and energy resources (both to domestic consumers and to exports).

Here and below in the text, an emergency means a partial or complete failure of a limited number of objects at the same time. The critical situation means situation, when the objects of the FEC (or a some energy system (ES)) practically all simultaneously have to function in an abnormal mode for example, especially cold days in a large part of the country or any other conditions that cause ESs to work in an abnormal regime). Accounting for the second requirement is associated with the need to carefully identify the critical objects (COs) of the FEC and ESs, i.e. those objects, partial or complete failure of which in different conditions can significantly reduce the production capacity of ESs and FEC and lead to significant shortages in the supply of appropriate types of energy. FEC and ESs can and should have different lists of COs at different times. This is due to the fact that the configuration of energy transport communications and the loading of nodes, both consumption and production, gradually change over time. Some objects may lose their significance over time, but new more significant objects may appear, the failure of which will have a critical impact on the production capacities of the ESs or the FEC of the country. The study of the interconnected work of the different ESs within the framework of a single FEC will make it possible to understand which COs from the lists of such objects of some ES can be included in the list of the COs of FEC. The analysis of the interconnected work of different energy systems within the framework of a single FEC will make it possible to understand which COs from the lists of such objects of individual energy systems can be included in the list of the COs of the FEC level. The criterion of such selection can be the level of negative consequences for consumers because of failure of a specific CO of some ES, taking into account the compensating abilities of the FEC to reduce the negative consequences (interchangeability of FER, diversification of their sources, etc.).

The study of critical infrastructures in the energy sector has become one of the important areas of scientific research. Many works are devoted to this question [1, 2 \& oth.]. This topic also concerns the materials of the European Commission [3] and the US Department of Energy [4]. Unfortunately, any estimates and model estimates in these documents are not present. Basically, there are discussions about the policy and organization of energy supplies, as well as the interaction between the elements of energy systems. In such works there is no access to specific objects due to the fragmentation of energy systems and their work not in the framework of a single complex, but on the basis of the principles of market trade.

In general, the identification of the COs in the FEC can effectively solve the problems of identifying and minimizing the consequences of implementing various types of threats that are fraught with crisis and 
emergency situations at the FEC, as well as the tasks of preparing these objects in advance for the duration of the specified situations. Equally important is the solution of the problem of concentration of material, monetary and human resources in solving the problems of increasing the sustainability of the functioning of the identified COs of FEC without sputtering such, as a rule, limited resources.

\section{Algorithm for the formation of the COs lists}

Today, the main role in the fuel and energy complex of Russia belongs to gas. Its share in the balance of boilerfurnace fuel (BFF) is $74 \%$ in Russia as a whole. However, for the regions of the European part and the Urals (where $88 \%$ of the Russian Federation's population live), this share in a number of regions reaches $90-95 \%$, and in some regions of the Russian Federation - up to $98-99 \%$. Given the dominant role of gas in the fuel and energy complex, at the first stage we will focus on the Unified Gas Supply System (UGSS) of the country (including export outlets of Russian gas beyond its borders and imports of imported gas to Russia). The example of the UGSS should address the following issues:

- development of a general algorithm for the identification COs of a some system;

- evaluation of negative consequences for the some system from partial or complete failure of various COs in the event of emergency on these objects;

- assessment of the role of specific COs in ensuring the operability of the some system under the large-scale emergency situations;

- formation of a list of specific measures to minimize the negative consequences from a decrease in the level of efficiency of each CO of the some ES;

- substantiation of the list of invariant measures to minimize the negative consequences of emergency situations on the COs of the ES, taking into account possible simultaneous combinations of emergencies on different objects.

From the standpoint of energy security, two types of objects can be assigned to critical objects of ES:

- objects whose shutdown can cause significant shortages of energy resources in the whole country (deficit in the relative amount of $\delta_{\text {sum }}$ and more of the total demand for this energy resource), such objects can be considered as the ES COs of the federal level;

- objects that are not included in the list of federal COs for the some ES, but the termination of their work, can cause significant shortfall of energy resource in at least one of the regions (deficit in relative amount of $\delta_{\text {reg }}$ or more of the total demand of the region for this energy resource). Such objects can be considered as the ES COs of the regional level.

As $\delta_{\text {sum }}$ for the gas industry, a value of $5 \%$ was assumed earlier in [5]. As $\delta_{\text {reg, }}$, in the first approximation, a value of $30 \%$ can be used. It should be understood that these values are still very arbitrary, for their comprehensive justification, special studies are needed.
The algorithm for the formation of the COs lists of the regional and federal levels for the some ES is presented in Fig. 1.

\section{Characteristic of the settlement network}

Let's consider the real situation in the Russian gas industry. In 2017, Russia produced 690 billion $\mathrm{m}^{3}$ of gas. 8 billion $\mathrm{m}^{3}$ of natural gas (from Central Asian countries and Azerbaijan) was imported. Domestic consumption (together with the gas sector's own needs) amounted to 472 billion $\mathrm{m}^{3}$, and exports amounted to 226 billion $\mathrm{m}^{3}$, including slightly more than 192 billion $\mathrm{m}^{3}$ to non-CIS

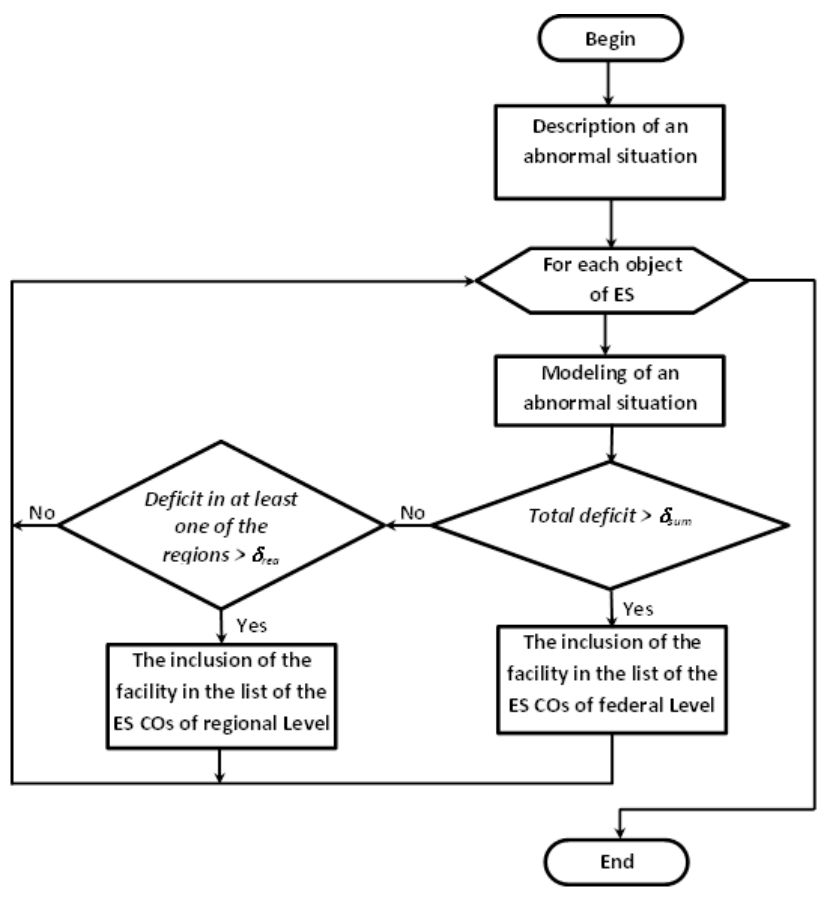

Fig. 1. Algorithm for the formation of the ES CFs lists of the regional and federal levels

countries. The country has an unified gas supply system (UGSS) with an extensive system of main gas pipelines covering most of the european part of Russia's territory. The existing territorial structure of the Russian gas supply system has a number of significant shortcomings. In fact, the main gas consumer within the country (the parts of its European part) does not have its own gas resources. All gas consumed here is mainly produced in the north areas of the Tyumen region (NATR), located in 2-2.5 thousand $\mathrm{km}$ from places of intensive gas consumption. Today, the NATR produces more than $85 \%$ of the total Russian gas, i.e. practically all Russian gas has to be transported for long distances by main gas pipelines with a colossal concentration of gas flows in one corridor. These corridors have a large number of crossings and bridges. The gas pipelines in one corridor can be located from each other at a very small distance. Currently, more than 20 potential crossings of main gas pipelines potentially dangerous for the operation of the UGSS can be identified in Russia. Violation of some of them may lead to a restriction of up to $85 \%$ of gas supply 
to domestic consumers in the country as a whole or to almost complete cessation of gas exports (while retaining a $50 \%$ restriction of gas supplies to domestic consumers).

In the studies carried out earlier [5,6] facilities (20 crossings of main gas pipelines) characterized as the COs of gas transmission network of Russia have already been shown. At the same time, the issue of the remaining facilities of the gas industry for their inclusion in the list of COs from the energy security standpoint has not yet been raised. Along with the major intersections of the main gas pipelines at nodal compressor stations and outside, the COs of the gas industry from the standpoint of its operability are the main compressor stations on the outputs from the gas fields and underground gas storages (UGS). At present, there are 22 UGSs in the Russian gas transmission network, 5 more UGSs are operating outside the Russian Federation ( 3 in Belarus, one in Armenia and Germany). Another 7 UGSs (in which Gazprom participates as a co-investor) operate in the gas pipeline network on the territory of the European states [7]. All these UGSs incorporated into a specially designed flow model gas industry (within the software "Oil and Gas in Russia") [5, 6, 8]. This software allows imitating all aspects of the functioning of not only the UGSS of Russia, but also the technologically related gas networks of European countries. The settlement scheme of the model contains 382 nodes, including the above UGSs, 28 gas sources (in the model these are the main compressor stations (CS), 64 gas consumers, 268 nodal compressor stations, and 628 arcs representing the corridors of main gas pipelines and single main gas pipelines, as well as outlets to distribution networks.

\section{Mathematical statement of the solution of the problem}

Mathematically, Russia's unified gas supply system is represented as a network that varies with time, whose nodes have the facilities for production, conversion and consumption of material flows relating the enterprises. When solving the problem of state estimation of the system after a disturbance the criterion of flow distribution optimality is represented by the minimum shortage of the energy resource for consumer at the minimum costs of its delivery.

A change in the state of system facilities requires solving the problem of flow distribution in the system in order to supply energy carriers to the maximum extent possible, i.e. the model can be formalized as a problem about the maximum flow [8-10]. Then it is necessary to add two fictitious nodes to the graph scheme: $\mathrm{O}$ - total source, $\mathrm{S}$ - total sink, and introduce additional sections connecting node $\mathrm{O}$ with all sources, and all consumers with node S. Mathematically, the stated problem has the following form:

$\max f$

$$
\begin{gathered}
\sum_{i \in N_{j}^{-}} x_{i j}-\sum_{i \in N_{j}^{-}} x_{j i}=\left\{\begin{array}{l}
-f, j=O \\
0, j \neq O, S \\
f, j=S
\end{array}\right. \\
0 \leq x_{i j} \leq d_{i j}
\end{gathered}
$$

Here $N_{j}^{+}$- a subset of edges incoming to node $j ; N_{j}^{-}$a subset of edges outgoing from node $j ; f$ - a value of the total flow in the network; $x_{i j}$ - a flow in edge $(i, j)$; $d_{i j}$ - constraints on the flow in edge $(i, j)$.

Problem (1)-(3) about the maximum flow in a general case has a non-unique solution. The next step suggests solving the problem of maximum flow of the minimum cost, i.e. the cost functional is minimized:

$$
\sum_{(i, j)} C_{i j} x_{i j} \rightarrow \min
$$

where $C_{i j}$ - price or specific costs of the energy resource transportation.

The comprehensive approach to solving the stated problems throughout the entire technological chain from receiving gas by the network to its transportation to the distribution network or export makes it possible to obtain the total estimate of the production capabilities of the entire system in the extreme conditions. Solution to the problem is represented by the values of gas shortage at the consumption nodes under emergency conditions. Based on these results, it becomes possible to build a list of all the facilities in the industry whose shutdown will lead to a potential gas shortage in the network. Rank this list by the relative size of the resource deficit in the network. By cutting off objects whose shutdown will lead to a potential gas deficit in the grid that is less than the previously assigned value, for example, at $5 \%$, we can get a list of the gas industry's COs. Such a list will also be ranked by the value of the impact on network capacity.

\section{The results of the research}

Appropriate studies have been carried out on the model of the gas industry of Russia described above. The initial conditions for the calculations were as follows: the average day of the maximum gas consumption in the network, based on statistics on gas consumption by regions in January 2017. In such days the network can be considered extremely tense with maximum load. The total flow of gas through the network on such days, taking into account export deliveries, amounted to 2250 $\mathrm{mln} \mathrm{m}^{3}$ approximately. The results of these studies showed that the potential gas shortage for consumers will be observed when each of the 441 gas objects in Russia is shut down (242 nodes and 199 arcs of the network settlement graph). From this list, 61 objects should be included in the list of gas industry COs of the federal level. Among them there are 25 arcs between nodal CSs and 36 nodes, including 30 nodal CSs, 5 main CSs on the outlets from large gas fields and one UGS. Information on the estimated values of the relative gas 
deficits in the network with the disconnection of specific nodes and arcs in ranked by the degree of reduction of the gas deficit is presented in Table 1 (the real names of the UGSS objects in this paper were replaced by conditional numbers).

From the data of Table 1 it can be seen that if each of the first eight objects of the ranked list of federal UGSS COs is disconnected, the relative gas deficit in the system may amount to about $20 \%$ of the required total supply. Disconnecting each of the following 15 objects can result in a gas flow restriction within $10-16 \%$. Disconnecting all other objects from the list of CFs can lead to a relative gas deficit in the system in the range of $5-9 \%$.

Table 1. Estimated relative gas deficits in the network at the most intense day of January, 2017, when federal UGSS COs

\begin{tabular}{|l|c|c|}
\hline $\begin{array}{c}\text { The ordinal number of the } \\
\text { ranked list of COs in the } \\
\text { calculated graph }\end{array}$ & $\begin{array}{c}\text { Object } \\
\text { type }\end{array}$ & $\begin{array}{c}\text { Relative gas deficit in } \\
\text { the system when the } \\
\text { CO is disconnected, } \%\end{array}$ \\
\hline $1,2,3,4$ & Node & 21 \\
\hline $5,6,7$ & Arc & 21 \\
\hline 8 & Node & 19 \\
\hline $9,13,14$ & Arc & 16 \\
\hline $10^{\text {a }}, 11,12,15$ & Node & 16 \\
\hline 16 & Arc & 12 \\
\hline $17,18,19,22,23$ & Node & 10 \\
\hline 20,21 & Arc & 10 \\
\hline 24 & Node & 9 \\
\hline $25,26,28^{\text {a }}$ & Node & 8 \\
\hline 27 & Arc & 8 \\
\hline $29,31,33,35,37,39,41$ & Arc & 7 \\
\hline $30^{\text {a }}, 32,34,36,38,40$ & Node & 7 \\
\hline $42,48,50$ & Arc & 6 \\
\hline $\begin{array}{l}43^{\text {a }}, 44^{\mathrm{a}}, 45,46^{\mathrm{b}}, 47,49, \\
51\end{array}$ & Node & 6 \\
\hline $52,55,56,59,60$ & Arc & 5 \\
\hline $53,54,57,58,61$ & Node & 5 \\
\hline $\begin{array}{l}\text { a } \\
\text { The object of gas extraction, i.e. to the maim CS at exits from gas } \\
\text { fields }\end{array}$ & & \\
b $\begin{array}{l}\text { Underground gas storage } \\
\text { Tnd }\end{array}$ & & \\
\hline
\end{tabular}

\section{Conclusion}

From the standpoint of ensuring the survivability of the gas industry and, in general, from the standpoint of ensuring the energy security of the country and its regions, it is first of all necessary to pay attention to the objects found in the result of the submitted studies from the list of the UGSS COs). Appropriate organizational measures should be taken to prevent emergencies in the first place at these facilities. A strategic task in the development of the industry may be the task of forming directions and concrete ways to reduce the critical importance of such COs for the potential productivity of the UGSS. With the development of the experience of identifying the COs in the gas industry for different time slices, the work can be continued in the part of identifying COs in other energy systems and in the fuel and energy complex as a whole.
The work was carried out within the framework of a scientific project III.17.5.1 of program of fundamental research of the SB RAS, reg. number AAAA-A17-117030310451-0.

\section{References}

1. Critical Infrastructure in the Energy Sector https://www.me.government.bg/en/themes/criticalinfrastructure-in-the-energy-sector-336-300.html

2. I.E. Anastasakis, Energy-critical infrastructure protection: "The case of Greece",

https://www.google.ru/url?sa $=$ t\&rct $=\mathrm{j} \& \mathrm{q}=\&$ esrc $=\mathrm{s} \& \mathrm{~s}$ ource $=$ web\&cd $=4 \& v e d=0$ ahUKEwjxsKe0vJvcAhVl GZoKHX_SCIMQFghGMAM\&url=https $\% 3 \mathrm{~A} \% 2 \mathrm{~F}$ $\% 2$ Fhrcak.srce.hr\%2Ffile\%2F251955\&usg=AOvVa w23toJ3XkfktOeJTwxmVxlk"

3. Protection of critical infrastructure / https://ec.europa.eu/energy/en/topics/infrastructure/pr otection-critical-infrastructure

4. Energy. Critical Infrastructure and Key Resources Sector-Specific Plan as input to the National Infrastructure Protection Plan (Redacted). May 2007. https://www.energy.gov/sites/prod/files/oeprod/Docu mentsandMedia/Energy_SSP_Public.pdf

5. Senderov S.M., Rabchuk V.I., Edelev A.V., Izv. RAN. Energetika [Proc. of the Russ. Acad. of Sciences. Pow. Engin.], 1, 70-78 (2016)

6. Senderov S., Edelev A.. Energy (2017). doi:10.1016/ J.ENERGY.2017.11.063

7. http://www.gazprom.ru/about/production/undergroun d-storage/

8. Voropai N.I., Senderov S.M., Edelev A.V., Energy (2012). doi:10.1016/j.energy.2011.07.038

9. Khramov A.V., Enikeyeva S.M., Khrustaleva N.M. \& oth., in Methods and models of research into the survivability of energy systems (Nauka Sib. Branch Novosibirsk, 1990, 86-91)

10. L.R. Ford Jr., D.R. Fulkerson, Flows in Networks (The Rand Corporation, Santa Monica, California, 1962) 